\title{
Cross-sectional Study on Blood Pressure Control in the Department of Nephrology of the Escola Paulista de Medicina - UNIFESP
}

\author{
João Batista de Freitas, Agostinho Tavares, Osvaldo Kohlmann Jr, Maria Tereza Zanella, \\ Artur Beltrame Ribeiro \\ São Paulo, SP - Brazil
}

\begin{abstract}
Objective - To assess hypertension control rates in a specialized university-affiliated medical department, the influence of sex, diabetes, and obesity on that control, and the strategies for the treatment of hypertension.
\end{abstract}

Methods - We carried out a cross-sectional study with 1,210 patients followed up for at least 6 months. Information was gathered from medical and nursing records and comprised the following data: sex, age, weight, height, abdominal and hip circumferences, blood pressure, and class and number of the antihypertensive drugs prescribed. To assess obesity, we used body mass index and waist/ hip ratio. Blood pressure was considered under control when its levels were below 140/90 $\mathrm{mmHg}$.

Results - The study consisted of $73 \%$ females and $27 \%$ males. Most females (31.7\%) were 50 to 59 years of age, and most males $(28.3 \%)$ were 60 to 69 years. The blood pressure control rate found was $20.9 \%$ for the 1,210 patients and $23.4 \%$ for the hypertensive diabetic patients $(n=290)$. Despite the low control rates found, $70 \%$ of the patients used 1 or 2 antihypertensive medications. A high prevalence of obesity (38\%) was observed, and females had a greater abdominal obesity index than males did (90\% vs 82\%, p<0.05). Patients with a greater body mass index had less control of blood pressure.

Conclusion - The percentage of hypertensive patients with controlled blood pressure levels was low and was associated with a high prevalence of obesity. These data indicate the need for reviewing the strategies of global treatment for hypertension.

Keywords: hypertension, blood pressure control, treatment

Universidade Federal de São Paulo - Escola Paulista de Medicina

Mailing address: Agostinho Tavares - Disciplina de Nefrologia - Rua Botucatu, 740 - 04023-900 - São Paulo, SP, Brazil - E-mail

English version by Stela Maris C. e Gandour
The estimated prevalence of arterial hypertension in Brazil is $15 \%$ to $20 \%{ }^{1}$. According to official data from 1996 , cardiovascular diseases are the major cause of morbidity and mortality in our country ${ }^{2}$. Even though arterial hypertension is the major risk factor for such diseases, little is known about its control in Brazil. The number of controlled hypertensive patients varies from $4 \%$ to $12 \%$ depending on the criteria used ${ }^{3}$. Among the patients under pharmacological treatment, however, the percentage of control varies from $20 \%$ to $50 \%{ }^{3-6}$. These data are not in accordance with the international literature that reports lower control rates for patients on treatment. According to the last NIH report ${ }^{7}$, of the developed countries, the USA has the greatest rate of control of high blood pressure (27.4\%), while England has the lowest $(5.9 \%)^{8}$. Among the developing countries, India and Zaire have control rates as low as $9 \%$ and $2.5 \%$, respectively ${ }^{8}$.

For these reasons, we aimed to assess blood pressure control rates in patients pharmacologically treated at the Clinic of Arterial Hypertension of the Discipline of Nephrology of the Escola Paulista de Medicina - UNIFESP. We also assessed the influence of sex, obesity, and diabetes, and the pharmacological strategy used to control high blood pressure.

\section{Methods}

We carried out a cross-sectional study on blood pressure control in patients older than 18 years and registered at the Clinic of Arterial Hypertension of the Discipline of Nephrology at the Hospital do Rim e Hipertensão, who received medical assistance through the Integrated Health System (Sistema Único de Saúde - SUS). The inclusion criteria were regular follow-up for at least 6 months and primary arterial hypertension. We excluded the patients who were participating in a clinical protocol and those with secondary arterial hypertension. Data were collected directly from the medical and nursing records on the day of the medical visit from January to May 2000. 
Demographic, anthropometric, and clinical parameters were analyzed. The first 2 included sex, age in years, weight in kilograms $(\mathrm{kg})$, height in meters $(\mathrm{m})$, and abdominal and hip circumferences in centimeters $(\mathrm{cm})$. Deriving from them, we calculated body mass index using the formula weight $(\mathrm{kg}) /$ height square $\left(\mathrm{m}^{2}\right)^{9}$, and the waist/hip ratio ${ }^{10}$. Obesity was classified based on body mass index according to the criteria of the World Health Organization ${ }^{11}$ as follows: below normal weight (<18.5), normal weight (18.5-24.9), preobese (25-29.9), obese I (30-34.9), obese II (35-39.9), and obese III $(\geq 40)$. The criteria for abdominal obesity used were the cut points of 0.95 for males and 0.85 for females ${ }^{12}$. The clinical parameters studied included the systolic and diastolic blood pressure values in $\mathrm{mmHg}$, the number and classes of the antihypertensive medications prescribed, and the diagnosis of diabetes mellitus. For blood pressure values, the means of 2 or more measurements in the sitting position were considered. The diagnostic, stratification, and blood pressure control criteria followed the recommendations of the III Brazilian Consensus on High Blood Pressure (III Consenso Brasileiro de Hipertensão Arterial) ${ }^{1}$ : normalbloodpressure $(<130 / 85 \mathrm{mmHg}$ ), borderline (130-139/85-89 $\mathrm{mmHg}$ ), mild hypertension (140-159/90-99 $\mathrm{mmHg}$ ), moderate (160-179/100-109 mmHg), severe ( $\geq 180 / 110 \mathrm{mmHg})$, and isolated systolic hypertension $(\geq 140 /<90 \mathrm{mmHg})$. For diabetic patients, the cut off values for normality were $130 / 85 \mathrm{~mm} \mathrm{Hg}$ and the individuals were considered diabetic if they had fasting glycemia $>126 \mathrm{mg} / \mathrm{dL}$ or if they were under treatment with oral antidiabetic drugs or insulin. The classes of antihypertensive drugs were defined as follows: diuretics (thiazide, potassium sparing, and loop diuretics), sympatholytic agents (beta-blockers, alpha-2-agonists, and alpha-1-blockers), calcium channel blockers, angiotensin-converting enzyme inhibitors, and angiotensin II antagonists.

The results were assessed using the Student $t$ test for comparing 2 quantitative means and the chi-square test for analyzing categorical data. The level of rejection of the null hypothesis was fixed as $5 \%$.

\section{Results}

Table I shows the demographic and anthropometric characteristics of the 1,210 patients studied [329 (27\%) males and 881 ( $73 \%)$ females], whose mean age was $55.3 \pm 12.4$ years and very similar for both sexes. Most males were 6069 years of age, and most females were 50-59 years (tab. II). The mean values of body mass index indicated that the population studied was in the borderline of the preobesity and obesity range (29 \pm 5 ), and that females had slightly higher values than those of the males with a marginal statistical significance $(\mathrm{p}=0.051)$. Body mass index distribution is shown in figure 1 , in which most (68\%) patients are in the preobesity and obesity I ranges. Anthropometric data show that most patients assessed had centripetal obesity. However, when the values of waist/hip ratio were compared between males and females, a greater number of

\begin{tabular}{|lccc|}
\hline \multicolumn{4}{|c|}{ Table I - Age and indices for assessing obesity in the study } \\
patients grouped by sex.
\end{tabular}

\begin{tabular}{|lcc|}
\hline \multicolumn{3}{|c|}{ Table II - Percentage distribution of the patients } \\
according to sex and age. \\
\hline Age & Males & Females \\
\hline $20-29$ & 5.8 & 2.3 \\
$30-39$ & 10 & 6.7 \\
$40-49$ & 16.4 & 20.8 \\
$50-59$ & 24.9 & 31.7 \\
$60-69$ & 28.3 & 27.2 \\
$70-79$ & 13.7 & 9.8 \\
$80-89$ & 0.9 & 1.5 \\
Total & 100 & 100 \\
\hline
\end{tabular}

females than males were above the recommended values $(p<0.05)$ (fig. 1).

In our hypertensive population, $20.9 \%$ of the patients had blood pressure control, while most patients had levels compatible with mild to moderate hypertension (fig. 2). The proportion of male and female patients controlling blood pressure was very similar (22.1\% and $20.4 \%$, respectively). For the hypertensive and diabetic patients, the percentage of individuals controlling blood pressure was very similar when values below $140 / 90 \mathrm{mmHg}$ were considered as the limit of normality (24.4\%). However, due to control values different from those of the general population, only $13.4 \%$ of the hypertensive diabetic patients properly controlled blood pressure (fig. 2). Control and distribution of blood pressure values also varied as a function of the indices of obesity quantification. Figure 3 shows that blood pressure control decreases and the proportion of severe hypertensive patients increases as the body mass index progresses from obesity I to obesity III.

We also observed that $70 \%$ of the patients had been prescribed 1 ormoremedications for blood pressure control, 1/3 of them being on monotherapy (fig. 4). When the blood pressure levels of the patients on monotherapy were analyzed, we observed that those using diuretics and sympatholytic agents did not have severe hypertension, unlike those individuals using calcium channel blockers, angiotensin-converting enzyme inhibitors, and angiotensin II antagonists (fig. 5). 


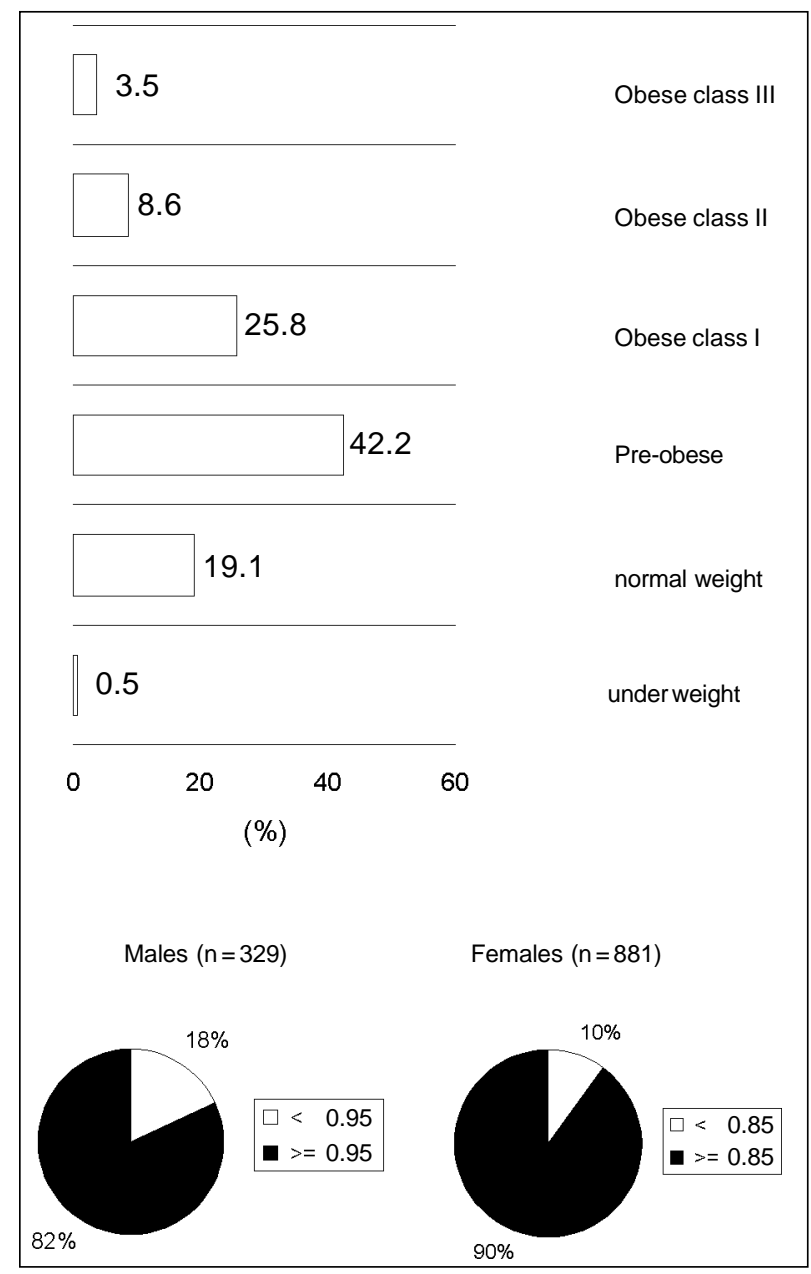

Fig. 1 - Percentage distribution of the patients $(\mathrm{n}=1.210)$ based on body mass index and waist/hip ratio according to sex.

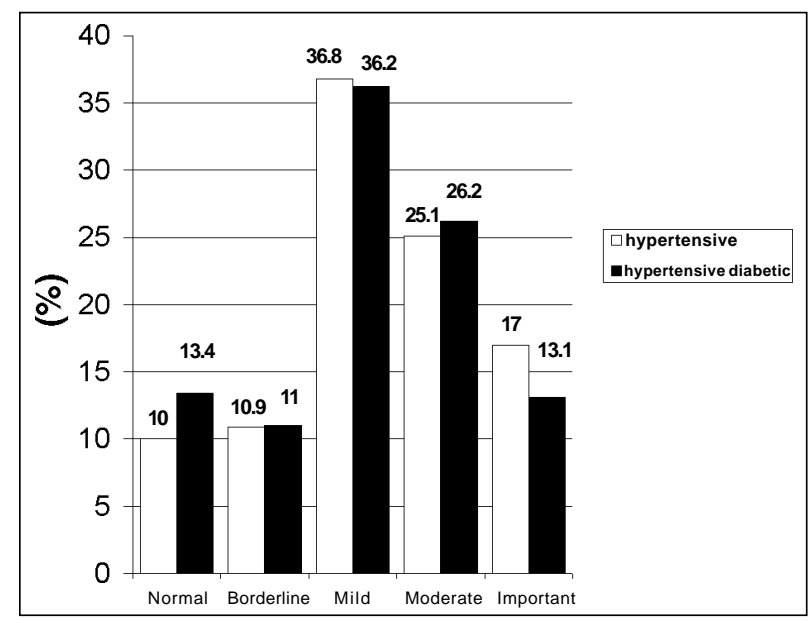

Fig. 2 - Percentage distribution of the hypertensive and hypertensive diabetic patients based on blood pressure levels. ${ }^{*}(p<0.05)$ vs males.

\section{Discussion}

The analysis of 1,210 medical and nursing records of hypertensive individuals showed that females were the great majority $(73 \%)$ of the patients in our service. This

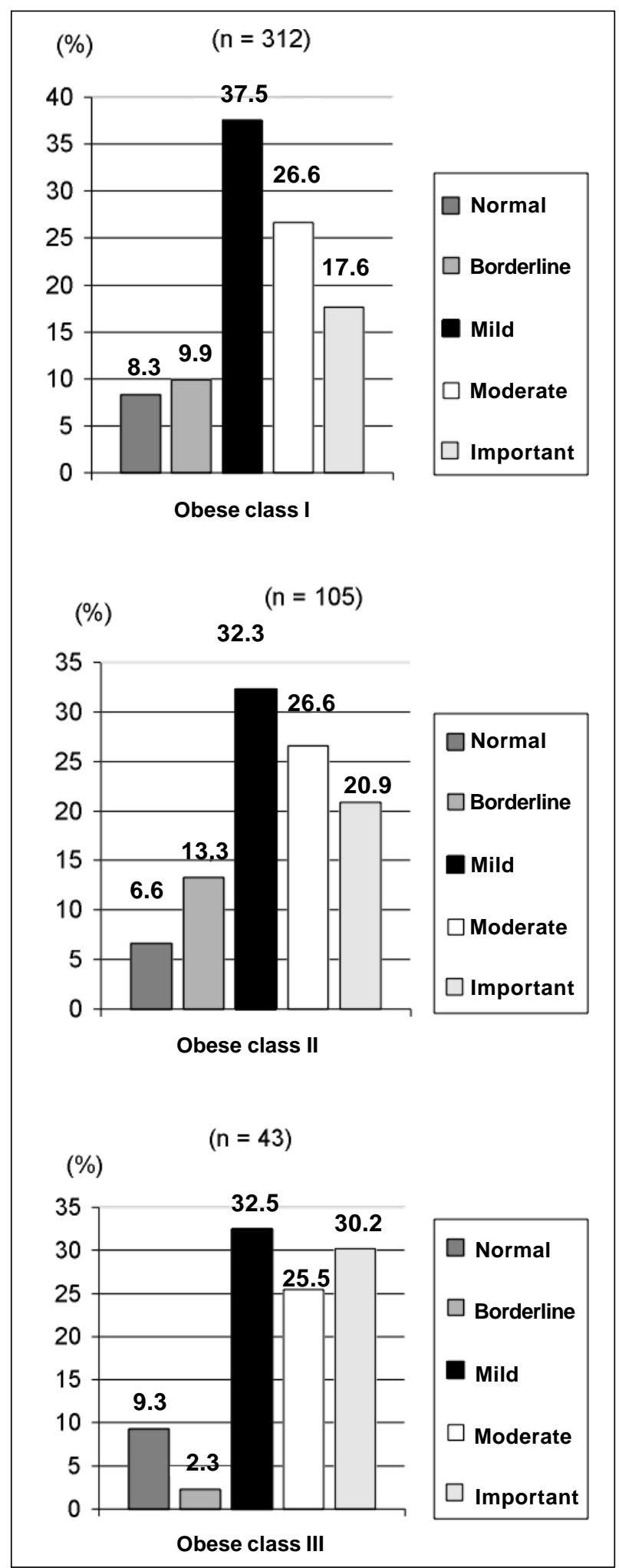

Fig. 3 - Percentage distribution of the obese patients $(n=460)$ based on body mass index and blood pressure levels.

does not seem to be explained by the fact that females have more time to look for medical assistance, because recent data from the Brazilian Institute of Geography and Statistics (Instituto Brasileiro de Geografia e Estatística - IBGE) showed that females are equal to males in the work force ${ }^{13}$. 


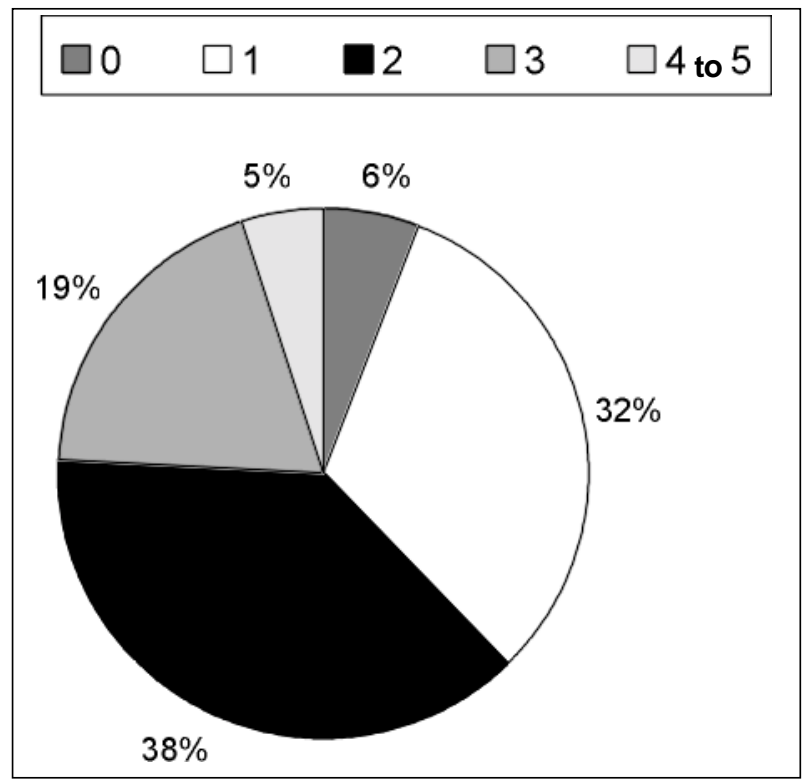

Fig. 4 - Percentage distribution of the patients $(n=1,210)$ according to the number of antihypertensive drugs prescribed.

Costa ${ }^{14}$ formulated the hypothesis that females are more aware than males in regard to their diseases and also more adherent to treatment. This may be partially confirmed by our analysis, because the greatest percentage of the male population was 60 to 69 years of age, while most females were 50 to 59 years of age, suggesting that females look for medical assistance earlier.

In regard to anthropometric data, the high mean values of body mass index are notable. When separating body mass index by categories, we observed that $38 \%$ of the population was obese and only $19.6 \%$ were within normal values. Even though the prevalence of obesity has increased in Brazil and other countries ${ }^{11}$, the prevalence observed in this study is much greater than that of the general Brazilian population, because data from IBGE of 1996/7 indicate a rate of obesity of $12.4 \%$ for the population of the Southeastern region ${ }^{15}$. Our data probably reflect the fact that obesity is a risk factor for arterial hypertension ${ }^{16}$ and that university-affiliated services tend to attract higher-risk patients. Even though body mass index has not diverged between males and females, the waist/hip relation showed greater abdominal obesity values in the female population. Several factors may explain this finding. Recent data showed that menopausal females have greater weight gain, mainly due to visceral and subcutaneous fat in the abdominal region ${ }^{17,18}$. Toth et al ${ }^{19}$ observed that females who had recently become menopausal had $28 \%$ more total body fat, $49 \%$ more visceral fat, and $22 \%$ more abdominal subcutaneous fat as compared with those of premenopausal females. Observing the distribution of the females in our study according to age, we may conclude that most of them were menopausal ( $70.4 \%$ above 50 years of age). In addition, other factors, such as number of children, socioeconomic level, and educational level, may also contribute to a greater fat deposition in the abdominal region ${ }^{17}$. These factors, however, were not assessed in our study.

Blood pressure control by maintaining its levels below 140/90 $\mathrm{mmHg}$ as recommended by the III Consenso Brasileiro de Hipertensão ${ }^{1}$ and the major international consensus ${ }^{7,20}$ was below our expectations. Only $20.9 \%$ of the hypertensive individuals studied had blood pressure levels within the normal range. The hypertensive diabetic patients had an even poorer control. Only $13.4 \%$ of them had blood pressure within the recommended levels, ie, below $130 / 85 \mathrm{mmHg}^{1}$. International and national data also show poor arterial hypertension control ${ }^{3,7,8}$. However, some Brazilian regional data with much smaller samples have better blood pressure control indices. Fuchs et al ${ }^{6}$ found $35.5 \%$ of the hypertensive patients controlled in a study carried out in the state of Rio Grande do Sul. Other Brazilian authors ${ }^{21,22}$ still report control indices of $32 \%$ and $50 \%$. Even though, these control indices are not promising, our data are notable because we are a university-affiliated, highly specialized service offering multiple professional services, which partially provides medication to the patients. The study by Silva et $\mathrm{al}^{5}$, who analyzed blood pressure control indices based only on diastolic blood pressure in a university-affiliated service, concluded that $32.9 \%$ of the hypertensive individuals controlled their blood pressure. We cannot, however, compare our results with those of the study by Silva et al ${ }^{5}$, because of the methodologies used. While the latter analyzed blood pressure control indices based only on diastolic blood pressure, our study included the assessment of systolic blood pressure.

Despite the difficulties of comparing these data among several studies, the difficulty in controlling blood pressure is clear. Several factors may have contributed to this poor control, from the patient's adherence to the proposed treatment to the efficacy of the treatment itself. The number of medications prescribed to our study population is noteworthy. Most patients (70\%) used only 1 or 2 antihypertensive drugs, and $42.1 \%$ of the patients were in stages 2 or 3 of hypertension (moderate or severe). The HOT Study ${ }^{23}$ showed that, for patients withmediumblood pressure levels $(161 / 98 \mathrm{mmHg})$, $63 \%$ required the association of medications to reduce arterial blood pressure to $144 / 85 \mathrm{mmHg}$. In our study, $74 \%$ of the patients required the association of antihypertensive drugs to maintain systolic blood pressure at $140 \mathrm{mmHg}$. Therefore, our data suggest that the antihypertensive medicamentous treatment in our service has been insufficient, mainly for the hypertensive diabetic patients who require lower blood pressure levels. On the other hand, most physicians and patients believe that mild to moderate hypertension may be easily controlled with monotherapy. This perception has changed with recent clinical trials, which have tried to control blood pressure within the recommended levels ${ }^{23,24}$.

Finally, our data show that the patients who were receiving monotherapy did not have severe hypertension if they were using diuretics (99\% thiazides) or sympatholytic agents (95\% beta-blockers). This apparently more efficient control is not due to a greater efficiency of the diuretics or 


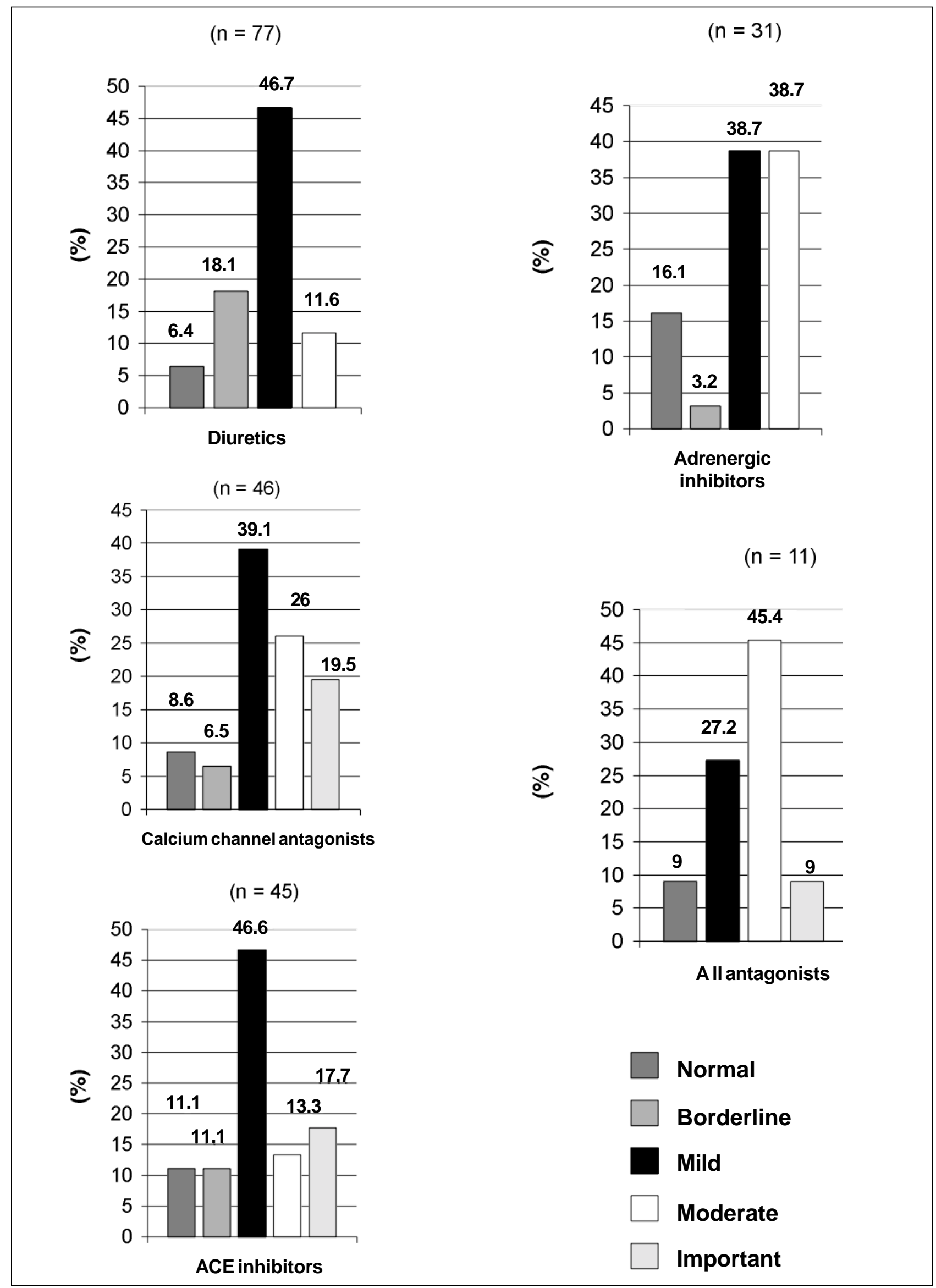

Fig. 5 - Percentage distribution of the patients receiving monotherapy $(n=210)$ based on blood pressure levels. 
sympatholytic agents, because all classes recommended for monotherapy are known to have a similar hypotensive efficacy ${ }^{1}$. Perhaps this may be explained by the cost of the medication. If the patient cannot get 1 medication for free, he may buy it; this does not happen with other more expensive hypotensive drugs.

In conclusion, we believe that the low blood pressure control indices found in our service are due to difficulties in treating arterial hypertension, to the greater severity of hypertension of the population assisted, to the high prevalence of obesity found, and to the lack of aggressive medicamentous treatment. It is clear that the institution of an antihypertensive treatment with a global focus is required to improve blood pressure control indices.

\section{References}

1. III Consenso brasileiro de hipertensão arterial. Rev Bras Clin Terap 1998; 24: 231-72.

2. Brasil. Ministério da Saúde. PNECHA. Doenças cardiovasculares. [Capturado 12 de outubro de 2000]. Disponível:http://www.saude.gov.br/programas/ cardio.htm

3. Brasil. Ministério da Saúde. Controle da hipertensão arterial. Uma proposta de integração ensino-serviço. Rio de Janeiro: CDCV/Nutes; 1993, cap. 2.

4. Carvalho JJM, Silva NAS, Oliveira JM, et al. Pressão arterial e grupos sociais. Estudo epidemiológico. Arq Bras Cardiol 1983; 40: 115-20.

5. Silva NAS, Aguiar GR, Nogueira AR, et al. Importância clínica dos custos hospitalares em pacientes com hipertensão arterial em tratamento num hospital universitário. Rev Saúde Pública 1986; 20: 293-302.

6. Fuchs FD, Moreira LB, Moraes RS, et al. Prevalência de hipertensão arterial sistêmica e fatores associados na região urbana de Porto Alegre: estudo de base populacional. Arq Bras Cardiol 1994; 63: 473-9.

7. National Institute of Health. The Sixth Report of the Joint National Committee on Detection, Evaluation, and Treatment of High Blood Pressure. NIH Public 1997.

8. Mancia G, Stella ML, Grassi G. New drugs for the treatment of hypertension. Curr Opin Cardiol 1999; 14: 375-80.

9. Stensland SH, Margolis S. Simplifying the calculation of body mass index for quick reference. J Am Diet Assoc 1990; 90: 856.

10. Mueller WH, Wear ML, Hanis CL, et al. Which measure of body fat distribution is best for epidemiologic research? Am J Epidemiol 1991; 133: 858-69.

11. World Health Organization. Obesity. Preventing and managing the global epidemic. Geneva (Switzerland): report of a WHO consultation on obesity; 1998.

12. Pouliot M-C, Després J-P, Lemieux S, et al. Waist circumference and abdominal sagittal diameter: best simple anthropometric indexes of abdominal visceral adipose tissue accumulation and related cardiovascular risk in men and women. Am J Cardiol 1994; 73: 460-8.
13. Brasil. Instituto Brasileiro de Geografia e Estatística - IBGE. PNAD - 1999. [Capturado em 12 de julho de 2000]. Disponível em http://www.ibge.gov.br/ ibge/estatística.htm

14. Costa EA. Hipertensão arterial como problema de massa no Brasil: caracteres epidemiológicos e fatores de risco. Ciênc e Cultura 1983; 35: 1643-9.

15. Monteiro CA, Conde WL. A tendência secular da obesidade segundo estratos sociais: Nordeste e Sudeste do Brasil, 1975-1989-1997. Arq Bras Endocrinol Metab 1999; 43: 186-94.

16. Schmieder RE, Meserli FH. Obesity hypertension. Med Clin North America 1987; 71: 991-1001.

17. Lahmann PH, Lissner L, Gullberg B, et al. Sociodemographic factors associated with long-term weight gain, current body fatness and central adiposity in Swedish women. Int J Obes 2000; 24: 685-94.

18. Tchernof A, Poehlman ET, Després JP. Body fat distribution, the menopause transition, and hormone replacement therapy. Diabetes e Metab 2000; 26: 12-20.

19. Toth MJ, Tchernof A, Sites CK, et al. Effect of menopausal status on body composition and abdominal fat distribution.Int J Obes 2000; 24: 226-31.

20. World Health Organization \& International Society of Hypertension. Guidelines for management of hypertension. J Hypertens 1999; 17: 151-83.

21. Carvalho JJM, Silva NAS, Oliveira JM, et al. Pressão arterial e grupos sociais. Estudo epidemiológico. Arq Bras Cardiol 1983; 40: 115-20.

22. Costa EA. Hipertensão arterial como problema de massa no Brasil: caracteres epidemiológicos e fatores de risco. Ciênc e Cultura 1983; 35: 1643-9.

23. Hansson L. The optimal blood pressure reduction. J Hypertens 1998; 14(Supp12): S55-S59.

24. Fox C. Diabetes and Hypertension: an era of clarity or confusion? J Hum Hypertens 1999; 13(Suppl 2): S9-S17. 